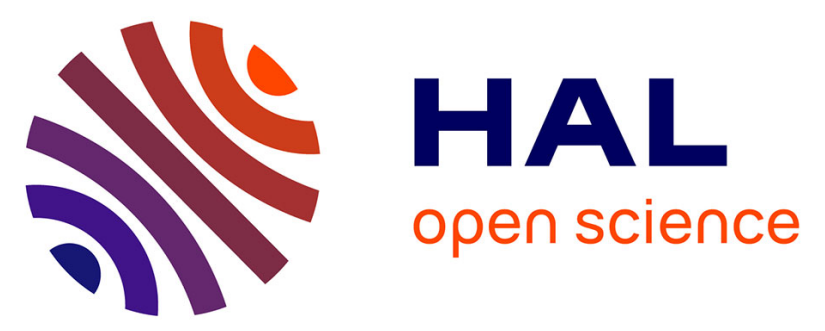

\title{
Formation of three-dimensional islands in the active region of InGaN based light emitting diodes using a growth interruption approach
}

Andrei F. F Tsatsulnikov, Wsevolod V. V Lundin, Alexei V. V Sakharov, Andrey E. E Nikolaev, E.E. E Zavarin, S.O. O Usov, Maria A. A Yagovkina, Martin Hÿtch, Maxim Korytov, Nikolay Cherkashin

\section{To cite this version:}

Andrei F. F Tsatsulnikov, Wsevolod V. V Lundin, Alexei V. V Sakharov, Andrey E. E Nikolaev, E.E. E Zavarin, et al.. Formation of three-dimensional islands in the active region of InGaN based light emitting diodes using a growth interruption approach. Science of advanced materials, 2015, 7 (8), pp.1629-1635. 10.1166/sam.2015.2277 . hal-01721151

\section{HAL Id: hal-01721151 \\ https://hal.science/hal-01721151}

Submitted on 11 Jun 2018

HAL is a multi-disciplinary open access archive for the deposit and dissemination of scientific research documents, whether they are published or not. The documents may come from teaching and research institutions in France or abroad, or from public or private research centers.
L'archive ouverte pluridisciplinaire HAL, est destinée au dépôt et à la diffusion de documents scientifiques de niveau recherche, publiés ou non, émanant des établissements d'enseignement et de recherche français ou étrangers, des laboratoires publics ou privés. 


\title{
Formation of Three-Dimensional Islands in the Active Region of InGaN Based Light Emitting Diodes Using a Growth Interruption Approach
}

\author{
A. F. Tsatsulnikov ${ }^{1, *}$, W. V. Lundin ${ }^{1}$, A. V. Sakharov ${ }^{1}$, A. E. Nikolaev ${ }^{1}$, E. E. Zavarin ${ }^{1}$, \\ S. O. Usov ${ }^{1,2}$, M. A. Yagovkina ${ }^{1}$, M. J. Hÿtch ${ }^{3}$, M. Korytov $^{3}$, and N. Cherkashin ${ }^{3}$ \\ ${ }^{1}$ Centre of Nanoheterostructure Physics, loffe Institute 194021, Politechnicheskaya 26, St-Petersburg, Russia \\ ${ }^{2}$ Submicron Heterostructures for Microelectronics, Research and Engineering Center, RAS 194021, \\ Politechnicheskaya 26, St-Petersburg, Russia \\ ${ }^{3}$ CEMES-CNRS/Université de Toulouse, 29 rue Jeanne Marvig, F-31055 Toulouse, France
}

\begin{abstract}
Here, we develop a technological approach to the formation of three-dimensional island-like structures in the active medium of InGaN/GaN based light emitting diodes with an enhanced efficiency with respect to reference quantum wells emitting at the same wavelengths. The reference structures contain two-dimensional $\ln _{x} \mathrm{Ga}_{1-x} \mathrm{~N}$ quantum wells with $x \leq 18 \%$ immediately overgrown after their formation. The method consists in the application of a growth interruption in $\mathrm{N}_{2}$ or $\mathrm{N}_{2}-\mathrm{H}_{2}$ mixed atmospheres at different $\mathrm{H}_{2}$ flows and times after the deposition of $\mathrm{In}_{0.18} \mathrm{Ga}_{0.82} \mathrm{~N}$ quantum wells, prior to their overgrowth by a $\mathrm{GaN}$ layer. The growth interruptions allow a controlled blue shift of the emission peak position with respect to that of the $\ln _{0.18} \mathrm{Ga}_{0.82} \mathrm{~N}$ structure. The integrated photoluminescence intensity of the so-formed structures is about 1.5 times higher than that of the reference structures emitting at the same peak wavelengths. Light emitting diode structures subjected to growth interruption exhibit higher external quantum efficiency than the reference structures emitting at the same wavelengths. We demonstrate that the observed phenomenon is related to a better charge carrier confinement within a quantum well due to the transformation of planar InGaN layers into laterally connected flat islands.
\end{abstract}

KEYWORDS: Metalorganic Vapor Phase Epitaxy, Growth Interruption, Indium Gallium Nitride, Quantum Wells, Quantum Dots, Light Emitting Diodes, Luminescence.

\section{INTRODUCTION}

The development of high efficiency and high brightness monolithic and hybrid III-V semiconductor based lightemitting diodes (LED) would pave the way to superior white LEDs capable of replacing all conventional light sources over the coming years. A dramatic reduction of internal and external losses in LEDs is targeted through a clear improvement of crystalline quality and a significant enhancement of light extraction along the entire process chain from semiconductor epitaxial layer growth to the application (e.g., light engines). To achieve this goal, new knowledge on the control of semiconductor properties on a near-atomistic scale is essential and requires novel crystal growth, design and technology according to the different materials.
An active medium of modern LEDs based on InGaN/GaN materials is composed of thin twodimensional (2D) layers serving as quantum wells (QWs) which are elastically strained and plastically relaxed to some extent. Carriers are free to migrate in the plane of the QWs that have a homogeneous distribution of indium and, thus, can easily reach and recombine at the cores of dislocations that exist at a high density in $\mathrm{GaN} / \mathrm{Al}_{2} \mathrm{O}_{3}$ materials. ${ }^{1,2}$ The presence of indium rich nanometer-sized inclusions within InGaN layers serving as quantum dots (QDs) might provide more effective localization of carriers: Their transport towards defect areas will be stopped and, thus, ensure a higher efficiency of LEDs despite a high dislocation density. Moreover, an inhomogeneous indium distribution within QWs has been demonstrated to allow an expansion of the emission range of InGaN-based LED, even towards red emission. ${ }^{3,4}$

In general, a local variation of In composition within InGaN materials is caused by phase separation that can be stimulated by nonequilibrium growth conditions. Changing 
the QW growth parameters (an indium flow or growth temperature, ${ }^{5-9}$ a $\mathrm{NH}_{3}$ flow, ${ }^{10}$ a hydrogen admixing ${ }^{11,12}$ ) or applying the QW post-growth treatment (an annealing in molecular nitrogen atmosphere, ${ }^{13}$ injecting $\mathrm{NH}_{3}$ in a cyclic periodic interrupted mode,${ }^{14}$ using growth interruption (GI) during deposition of InGaN QW, ${ }^{15}$ changing the growth conditions of a GaN layer covering the InGaN $\mathrm{QW}^{16}$ ) all strongly affect phase separation.

Despite obvious advantages, an inhomogeneous indium distribution within an InGaN layer provokes the local formation of additional dislocations that might deteriorate LED properties. ${ }^{17}$ The formation of laterally extended InGaN islands, instead of a continuous layer, can be considered as an alternative to a phase separation approach. Recently, a possibility to form InGaN islands under an external stress field has been demonstrated. ${ }^{18}$ However, such a specially designed heterostructure inherently contains a high density of defects.

In this work, we exploit a chemical activity of hydrogen atmosphere to form islands from two-dimensional layers. For this, we studied optical and morphological properties of metalorganic vapor phase epitaxy grown InGaN/GaN quantum wells subjected to growth interruptions in pure nitrogen or nitrogen-hydrogen mixed atmospheres prior to their overgrowth by a GaN layer. An evolution of indium composition, thickness and morphology of InGaN quantum wells was followed as a function of growth interruption time/hydrogen flow and compared with photo- and electroluminescence data.

\section{EXPERIMENTAL DETAILS}

Epitaxial structures were grown using two metalorganic vapor phase epitaxy (MOVPE) systems with horizontal reactor geometry: standard AIX2000HT with Planetary Reactor and home developed Dragon-125 MOVPE system with horizontal-flow inductively heated single-wafer reactor. Detailed growth investigations carried out during the last few years show that both of these MOVPE systems ensure the same results provided the same growth regimes and conditions. ${ }^{19,20}$ Ammonia, trimethylgallium (TMGa), triethylgallium (TEGa), trimethylindium (TMIn), trimethylaluminum (TMAl), biscyclopentadienylmagnesium $\left(\mathrm{Cp}_{2} \mathrm{Mg}\right)$, and silane $\left(\mathrm{SiH}_{4}\right)$ were used as precursors. Both reactors were equipped with in-situ optical reflectance monitoring (ORM) systems. Growth experiments were performed on (0001) sapphire substrates utilizing the conventional low-temperature $\mathrm{GaN}$ nucleation technique. ${ }^{1}$

Two series of samples were grown. The samples from the first series were intended for optical investigations and do not contain $p$-type AlGaN current blocking layer and GaN contact layer to avoid their possible strong effect on the photoluminescence data. Each structure contains five InGaN quantum wells separated by $\mathrm{GaN}$ barriers with a period of $12 \mathrm{~nm}$. The series is divided into three sets.
The first set contains InGaN QWs that were overgrown by a GaN layer immediately after their formation (Table I, set 1). The reference structure contains $3 \mathrm{~nm}$-thick InGaN layers grown at $760{ }^{\circ} \mathrm{C}$ with a TEGa flow of $250 \mathrm{sccm}$ and ammonia flow of $7 \mathrm{slm}$ (Table I, set 1, Ref.). Other structures from the set 1 contain QWs grown at a higher temperature, a lower In flow or a shorter time (Table I, set 1, O2-O6). The InGaN QWs from the set 2 and 3 were grown at similar to the Reference structure conditions and then subjected to a GI prior to their overgrowth by a GaN layer applied either in nitrogen $\left(\mathrm{N}_{2}\right)$ (Table I, set 2) or nitrogen/hydrogen mixed $\left(\mathrm{N}_{2}+\mathrm{H}_{2}\right)$ atmospheres (Table I, set 3 ) at different GI time/hydrogen flow conditions.

The second series of samples was dedicated to electrooptical investigations. An active region of the LED structures was composed of a single InGaN QW embedded between an InGaN/GaN short-period superlattice (SPSL) lying beneath and a $p$-type AlGaN current blocking layer and $\mathrm{GaN}$ contact layer lying above. The SPSLs were formed by applying cycle GIs during the growth of a thick InGaN layer. The details of the growth procedure and the properties of the InGaN/GaN SPSL have been described previously. ${ }^{21,22}$ The series is divided into two sets. The first set contains $3.8 \mathrm{~nm}$-thick $\mathrm{In}_{x} \mathrm{Ga}_{1-x} \mathrm{~N}$ QWs with $x \leq 18 \%$ that were overgrown by a GaN layer immediately after their formation (Table II, LED-Ref, LEDRef1, LED-Ref2). The QWs in the LED-Ref, LED-Ref1 and LED-Ref2 structure were grown at $760{ }^{\circ} \mathrm{C}, 765{ }^{\circ} \mathrm{C}$ and $770{ }^{\circ} \mathrm{C}$, respectively. The InGaN QWs from set 2 were grown at similar conditions to the LED-Ref structure and then subjected to a GI prior to their overgrowth by a $\mathrm{GaN}$ layer applied in nitrogen nitrogen/hydrogen mixed $\left(\mathrm{N}_{2}+\mathrm{H}_{2}\right)$ atmospheres at different GI time/hydrogen flow conditions.

All structures were studied by various characterization methods, including X-ray diffractometry, transmission electron microscopy (TEM) and spectroscopy of photoluminescence (PL) and electroluminescence (EL). An analysis of X-ray diffraction spectra allowed a precise determination of an $\mathrm{InGaN} / \mathrm{GaN}$ period thickness and a weighted In composition $\left(x_{\langle\mathrm{In}\rangle}\right)$ defined as $x_{\langle\mathrm{In}\rangle}=x_{\mathrm{InGaN}} \times$ $d_{Q W} /\left(d_{\mathrm{QW}}+d_{\text {barr }}\right)$, where $x_{\text {InGaN }}$ is an In content in a $\mathrm{QW}$, $d_{\mathrm{QW}}$ and $d_{\text {barr }}$ are QW and barrier thicknesses, respectively. The PL investigations allowed an estimation of the PL spectrum peak position, its full width on a half maximum (FWHM) and its integral intensity as function of QW growth parameters and GIs. The PL spectra were recorded in the temperature range from $10 \mathrm{~K}$ to $300 \mathrm{~K}$. Geometric Phase Analysis (GPA) ${ }^{23}$ of high resolution transmission electron microscopy (HRTEM) images has been applied to map strain with a subnanometer spatial resolution allowing to extract the alloy composition and thickness variations within QWs. Weak-Beam Darkfield (WBDF) TEM technique has been used to follow crystalline quality of the structures. Cross-sectional (CS) 
Table I. Optical and structural properties of the multi quantum well (MQW) samples.

\begin{tabular}{|c|c|c|c|c|c|c|c|c|c|c|c|}
\hline Set & Sample & $\begin{array}{c}\text { QW } \\
\text { growth } \\
\text { time, sec }\end{array}$ & $\begin{array}{c}\text { TMI } \\
\text { flow, sccm }\end{array}$ & $\begin{array}{c}\text { GI } \\
\text { time, } \\
\text { sec }\end{array}$ & $\begin{array}{c}\mathrm{H}_{2} \\
\text { flow, } \\
\text { slm }\end{array}$ & $\begin{array}{c}\text { QW } \\
\text { growth } \mathrm{T} \text {, } \\
{ }^{\circ} \mathrm{C}\end{array}$ & $\begin{array}{l}\text { Weighted in } \\
\text { content, \% }\end{array}$ & $\begin{array}{l}\text { QW } \\
\text { period, } \\
\mathrm{nm}\end{array}$ & $\begin{array}{c}\text { PL } \\
\text { peak } \\
(300 \mathrm{~K}), \mathrm{nm}\end{array}$ & $\begin{array}{c}\text { FWHM } \\
(300 \mathrm{~K} / 10 \mathrm{~K}), \mathrm{nm}\end{array}$ & $\begin{array}{c}\text { Integral } \\
\text { PL intensity, } \\
\text { arb.un. }\end{array}$ \\
\hline \multirow[t]{6}{*}{ 1. No GIs } & Ref. & 87 & 150 & 0 & 0 & 760 & 4.9 & 12.1 & 503 & $26 / 15$ & 50 \\
\hline & $\mathrm{O} 2$ & 87 & 75 & 0 & 0 & 760 & 4.1 & 12.0 & 472 & $19 / 10$ & 103 \\
\hline & $\mathrm{O} 3$ & 65 & 150 & 0 & 0 & 760 & 4.1 & 11.6 & 480 & $22 / 11$ & 59 \\
\hline & $\mathrm{O} 4$ & 53 & 150 & 0 & 0 & 760 & 3.5 & 11.1 & 461 & $20 / 11$ & 68 \\
\hline & O5 & 87 & 150 & 0 & 0 & 777 & 4.1 & 12.1 & 473 & $21 / 10$ & 134 \\
\hline & O6 & 87 & 150 & 0 & 0 & 784 & 3.6 & 12.1 & 454 & $17 / 9.5$ & 186 \\
\hline \multirow{3}{*}{ 2. GIs in $\mathrm{N}_{2}$} & $\mathrm{~N} 2$ & 87 & 150 & 64 & 0 & 760 & 4.1 & 12 & 484 & $25 / 13$ & 83 \\
\hline & N3 & 87 & 150 & 128 & 0 & 760 & 3.3 & 12 & 472 & $25 / 16$ & 136 \\
\hline & N4 & 87 & 150 & 256 & 0 & 760 & 2.0 & 11.8 & 470 & $28 / 22$ & 178 \\
\hline \multirow[t]{4}{*}{ 3. GIs in $\mathrm{N}_{2}+\mathrm{H}_{2}$} & $\mathrm{H} 2$ & 87 & 150 & 20 & 1 & 760 & 3.5 & 12 & 484 & $28 / 19$ & 94 \\
\hline & $\mathrm{H} 3$ & 87 & 150 & 20 & 2 & 760 & 2.1 & 11.9 & 473 & $26 / 18$ & 141 \\
\hline & $\mathrm{H} 4$ & 87 & 150 & 20 & 4 & 760 & 1.2 & 12 & 461 & $30 / 28$ & 171 \\
\hline & $\mathrm{H} 5$ & 87 & 150 & 20 & 8 & 760 & 0.26 & 7.2 & 432 & $24 / 30$ & 124 \\
\hline
\end{tabular}

$(5 \overline{4} \overline{1} 0)$ TEM specimens were prepared by tripod mechanical polishing followed by $\mathrm{Ar}^{+}$ion milling. The experiments were performed at $200 \mathrm{kV}$ in the SACTEMToulouse (Tecnai-FEI) microscope, equipped with image aberration corrector (CEOS). The HRTEM images were analyzed using GPA Phase 3.5 (HREM Research Inc.), plug-ins for the image processing package Digital Micrograph (Gatan Inc.). The X-ray diffraction investigations were performed on a D8Discover high resolution X-ray diffractometer (Bruker AXS, Germany). Photoluminescence spectra were recorded under the excitation by the $\mathrm{He}-\mathrm{Cd}$ laser with a wavelength of $325 \mathrm{~nm}$ and a power density of radiation equal to $25 \mathrm{~mW} / \mathrm{cm}^{2}$. Closed cycle helium cryostat was used for investigations of the PL in the temperature range from 10 to $300 \mathrm{~K}$. Electroluminescence investigations have been carried out on a wafer using indium contacts with a contact area of about $0.4 \mathrm{~mm}^{2}$.

\section{RESULTS}

\subsection{PL Investigations of MQW Structures}

Let us consider the first set of samples containing QWs grown without GIs (Table I, Ref. and O2-O6). The reference structure has a PL peak position at $503 \mathrm{~nm}$ and integral PL intensity of 50. It can be seen that decreasing the QW deposition time (O3, O4), the In flow (O2) or increasing the QW growth temperature $(\mathrm{O} 5, \mathrm{O} 6)$ with respect to the reference structure leads to a blue shift of the emission peak, a decrease in the FWHM and to an increase in the integral PL intensity. The effect is more pronounced for the structure containing a $\mathrm{QW}$ grown at the highest temperature of $784{ }^{\circ} \mathrm{C}(\mathrm{O} 6)$. A comparison between PL and X-ray data leads to the conclusion that this effect is induced by a change in only one QW characteristic with respect to the reference structure: a decrease in the QW thickness $(\mathrm{O} 3, \mathrm{O} 4)$ or a decrease in the QW composition (O2, O5, O6), respectively. Such behaviour of the emission is conventional in the considered range of wavelengths. ${ }^{24,25}$

The data on the evolution of the composition/thickness and optical parameters of the structures with QWs subjected to GIs in $\mathrm{N}_{2}$ atmosphere as function of a GI time are summarized in Table I, set 2. A GI in $\mathrm{N}_{2}$ atmosphere leads to a blue shift of the emission peak, an increase in the integral PL spectrum intensity (N2-N4), a decrease in the weighted indium composition and the period thickness. The effect is more pronounced for the structure subjected to the longest GI time of $256 \mathrm{sec}(\mathrm{N} 4)$. In contrast to the structures from the set 1 , a GI in $\mathrm{N}_{2}$ atmosphere either weakly affects the FWHMs of the PL spectra (N2, N3) or leads even to an increase in the FWHM of a PL spectrum (N4) with respect to the reference structure. It is worth noting that the integrated PL intensity of the N4 sample is 1.3 times higher than that of the O5 sample emitting in the similar range of $470 \mathrm{~nm}$.

As such, the fact might indicate a variation of a QW thickness in the N4 sample rather than an essential decrease of an average indium composition within the QW. A combination of PL and X-ray data allows us to conclude that a GI in $\mathrm{N}_{2}$ atmosphere affects both a QW thickness and composition as well as its morphology, provided that the GI time is long enough.

The last set of samples from this series contains QWs subjected to a GI in $\mathrm{N}_{2}+\mathrm{H}_{2}$ atmosphere during $20 \mathrm{sec}$ at different hydrogen flows (Table I, set 3). Qualitatively, the impact of a GI in $\mathrm{N}_{2}+\mathrm{H}_{2}$ atmosphere on the modification of an emission peak position, a PL integral intensity, a weighted In composition and a period thickness is similar to that observed for the N2-N4 samples. However, the effect is much more pronounced in spite of the considerably shorter time of a GI and becomes stronger as a hydrogen flow increases. The most apparent effect of a QW thickness/morphology and composition modification is observed for the H5 sample. The H5 sample is characterized by the essential blue shift of the PL peak position 
(down to $432 \mathrm{~nm}$ ), the decrease of the period thickness (down to $7.2 \mathrm{~nm}$ ) and a weighted In composition (down to 0.26) accompanied with the decrease of the integrated PL intensity with respect to the $\mathrm{H} 4$ sample. The sample H3, having the emission peak position at $473 \mathrm{~nm}$, is characterized by better emission efficiency than that of the samples $\mathrm{O} 2$ and N3 emitting in the same wavelength range. Therefore, we can conclude that an admixing of $\mathrm{H}_{2}$ accelerates the effect of a GI and may enhance optical properties of the structures emitting in the blue wavelength range.

The transformation of a two-dimensional layer into islands and/or QDs under GI is confirmed by a comparison of the temperature dependence of the PL spectra of the samples grown with different GIs (H3, H4 and H5) with respect to the reference structure (Ref) (Fig. 1). First, the slope of the temperature dependence of the integral PL intensity of a PL spectra allows the localization energy $\left(E_{\text {loc }}\right)$ of the carriers in a structure to be estimated. ${ }^{26,27}$ According to the integral PL intensity graphs plotted as function of $(1 / T)$ for Ref, $\mathrm{H} 3, \mathrm{H} 4$ and $\mathrm{H} 5$ samples, the $E_{\text {loc }}$ of the corresponding structures were found to be of $10 \mathrm{meV}, 15 \mathrm{meV}, 23 \mathrm{meV}$ and $30 \mathrm{meV}$, respectively. Thus, a GI in the $\mathrm{N}_{2}+\mathrm{H}_{2}$ atmosphere gives rise to a higher localization energy than in the reference structure. The effect becomes more evident as the hydrogen flow increases. The observed phenomenon can be explained by a partial conversion of $\mathrm{InGaN}$ to $\mathrm{GaN}^{28}$ at the surface of the InGaN QW. As a result, the effective thickness of the InGaN QW decreases and a very thin (about 1-2 nm thick) GaN layer of a varying thickness is formed above. In the case of narrow QWs this conversion leads to a partial transformation of the continuous 2D InGaN QW to 3D islands.

It is seen a principal change in the temperature dependence of the FWHMs of the structure PL spectra as a $\mathrm{H}_{2}$ flow increases (Fig. 1, insert). The FWHMs of the Ref and

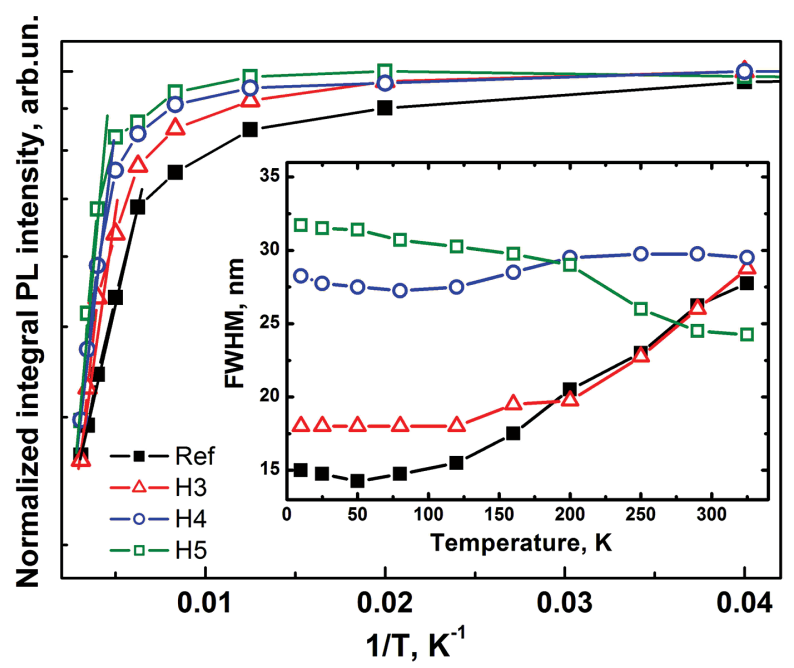

Fig. 1. Temperature dependence of the integral PL intensities and FWHM for the MQW samples grown without and with GIs in the $\mathrm{H}_{2}+\mathrm{N}_{2}$ atmosphere.
H3 samples increase with the temperature. This is a typical for a QW behavior. ${ }^{29,30}$ However, the temperature slope becomes less pronounced for the $\mathrm{H} 3$ sample, is quasi zero for the H4 sample and changes its sign for the H5 sample. Thus, such a temperature dependence of the FWHMs reflects an enhancement in the formation of islands in the structures subjected to GIs in $\mathrm{N}_{2}+\mathrm{H}_{2}$ atmosphere as the hydrogen flow increases.

It should be noted that the two sets of structures $\mathrm{O} 2$, N3, H3 and O3, N2, H2 have similar emission peak positions at wavelengths of 472-473 and 480-484 nm, respectively (Table I). An increase in the FWHM along with an increase in the integral photoluminescence intensity by a factor of 1.5 for the structures subjected to a GI with respect to the reference structures might be related to a transformation of the 2D InGaN layer into 3D islands. Therefore, strong modification of the structural and optical properties of the InGaN QWs subjected to a GI should affect the properties and efficiency of a LED structures.

\subsection{LED Structures}

\subsubsection{Electroluminescence Investigations}

The EL and structural properties of the LED samples are summarized in Table II. The samples contain QWs grown without a GI (LED-Ref, LED-Ref1 and LED-Ref2), QWs subjected to a GI in the $\mathrm{N}_{2}(\mathrm{LED}-\mathrm{H} 4)$ or in the $\mathrm{N}_{2}+\mathrm{H}_{2}$ (LED-H1, H2, H3, H5, H6) atmospheres during different times and at different hydrogen flows. The EL properties of the structures are described by an EL peak position, a FWHM of the EL spectra (measured at a low pump current of $10 \mathrm{~mA}$ ) and an external quantum efficiency (EQE) (measured at a high pump current of $100 \mathrm{~mA}$ ) obtained by on-wafer measurements.

The reference structures LED-Ref, LED-Ref1 and LEDRef2 have an EL peak position at 494, 480, $470 \mathrm{~nm}$, a FWHM of 25, 25, $26 \mathrm{~nm}$ and an EQE of 3.55, 4.74 and 5.2, respectively (Table II). The observed blue shift of an EL peak position and an increase in the EQE with respect to the LED-Ref structure should be related to a decrease in the In composition within a QW as the QW growth temperature increases.

A GI applied in the $\mathrm{N}_{2}$ atmosphere during $16 \mathrm{sec}$ after the formation of a QW grown at similar to the LED-Ref structure conditions (LED-H4) gives rise to a short wavelength shift in the emission peak position, an increase in the EQE and does not affect the FWHM of the spectrum with respect to the LED-Ref samples. During a GI, an addition of even a small amount of a $\mathrm{H}_{2}$ flow into the atmosphere amplifies a short wavelength shift, an increase in the EQE and results in an increase in the FWHM of the spectrum (LED-H5). Moreover, the effect is more pronounced for a higher $\mathrm{H}_{2}$ flow of $5.5 \mathrm{slm}$ (LED-H6). The similar phenomenon is observed as function of GI time at the same $\mathrm{H}_{2}$ flow of $5.5 \mathrm{slm}$ (LED-H1, $\mathrm{H} 3$, and H6). Indeed, the longer the GI is, the stronger 
Table II. Electroluminescence and structural properties of the LED samples.

\begin{tabular}{|c|c|c|c|c|c|c|c|}
\hline Sample & $\begin{array}{l}\text { GI time, } \\
\text { sec }\end{array}$ & $\begin{array}{l}\mathrm{H}_{2} \text { flow, } \\
\text { slm }\end{array}$ & $\begin{array}{c}\text { QW } \\
\text { thickness }{ }^{* *}, \mathrm{~nm}\end{array}$ & $\begin{array}{c}\mathrm{QW} \\
\text { in content }{ }^{* * * *}, \%\end{array}$ & $\begin{array}{c}\text { EL peak } \\
\text { wavelength, nm }\end{array}$ & $\begin{array}{c}\text { FWHM } \\
(10 \mathrm{~mA}), \mathrm{nm}\end{array}$ & $\begin{array}{c}\mathrm{EQE}(100 \mathrm{~mA}), \\
\text { arb.un. }\end{array}$ \\
\hline LED-ref & 0 & 0 & 3.8 & 18 & 494 & 25 & 3.55 \\
\hline LED-Ref1 & & & $3.8^{*}$ & 16 & 480 & 25 & 4.74 \\
\hline LED-Ref2 & & & $3.8^{*}$ & 15 & 470 & 26 & 5.2 \\
\hline LED-H1 & 3 & 5.5 & 3.5 & 16 & 488 & 24 & 4.15 \\
\hline LED-H2 & & 11 & $1.4-2.8^{* * *}$ & 16 & 474 & 30 & 4.85 \\
\hline LED-H3 & 6 & 5.5 & $1.7-3^{* * *}$ & 16 & 481 & 26 & 4.82 \\
\hline LED-H4 & 16 & 0 & 3.5 & 16 & 489 & 23 & 4.0 \\
\hline LED-H5 & & 1.8 & - & - & 476 & 30 & 4.16 \\
\hline LED-H6 & & 5.5 & $1.4-3.4^{* * *}$ & 16 & 469 & 30 & 5.71 \\
\hline
\end{tabular}

Notes: *estimated using a growth rate calibration, ${ }^{* *} \pm 0.2 \mathrm{~nm},{ }^{* * *}$ minimal and maximal QW thickness is indicated, ${ }^{* * * *} \pm 1 \%$.

the short wavelength shift of an EL peak position, the larger the FWHM and the higher the EQE. Generally, the EL properties of the structures are influenced by a total GI impact that can be defined as a product of the $\mathrm{H}_{2}$ flow and the GI time. However, the structures with similar EL peak wavelengths (LED-H2/LED-H5 or LEDH1/LED-H4) do not demonstrate similar EQE and vice versa (LED-H1/LED-H5 or LED-H2/LED-H3). A compromise between a desired range of the emission wavelengths and EQE can be reached provided that an optimal total GI impact has been found.

Figure 2 shows the graphs of the evolution of an EQE as function of a pump current corresponding to the reference structures LED-Ref (black solid line), LED-Ref1 (red short dash line), and LED-Ref2 (violet short dot line). The EQE of the LED-Ref and LED-Ref1 structure rapidly increases at the $0-40 \mathrm{~mA}$ current range and saturates/slightly decreases with a further increase of the current that is typical for GaN-based LEDs. ${ }^{31}$ However, the structures subjected to a GI exhibit an enhanced EQE with respect to the reference structures emitting at the same wavelengths. Indeed, an EQE of the LED-H3 (blue dot

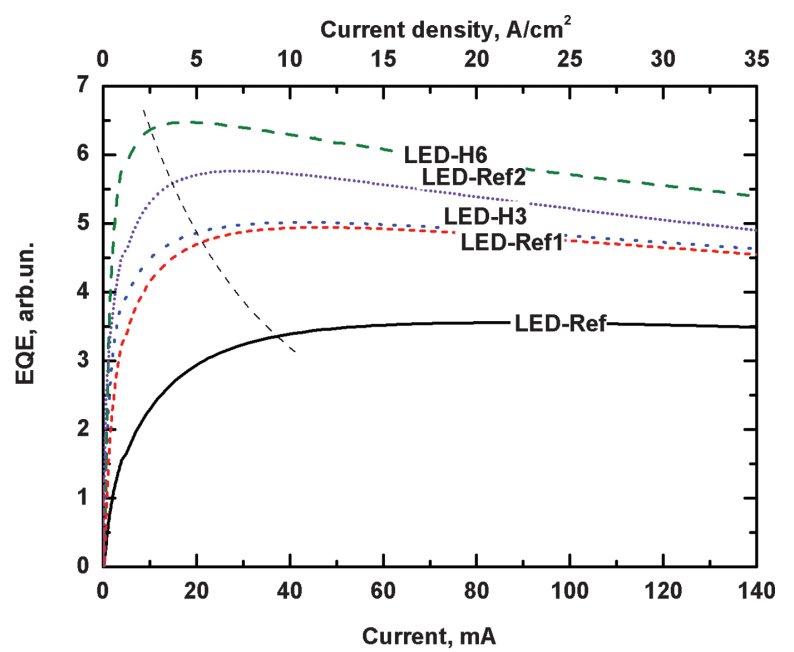

Fig. 2. Current dependences of the EQE for LED structures grown with different GIs. line) and LED-H6 (green dash line) structures increases more rapidly and reaches a higher maximum value at a lower current with respect to the reference LED-Ref1 and LED-Ref2 structures emitting at the same wavelengths of $480 \mathrm{~nm}$ and $470 \mathrm{~nm}$, respectively. The effect is more pronounced for the LED-H6 structure subjected to a longer GI time and exhibiting a 1.2 times higher $\mathrm{EQE}$ at low pump current than the LED-Ref2 structure.

The EQE current dependence of the reference structures is typical for a QW with a homogeneous indium distribution. At any pump current, carriers are free to move within such QWs and may reach non-radiative centres (cores of dislocations). At a low current, this event has a smaller probability than at a higher current and the EQE increases with the current. In a high current range, an excess of carriers is consumed by dislocation cores which prevents the $\mathrm{EQE}$ from rising. Generally, an $\mathrm{EQE}$ saturation value is related to the density of dislocations present in the structure. At the same current, a relative increase in the $\mathrm{EQE}$ observed in the structures subjected to a GI indicates a decrease in the QW effective indium composition and an enhanced confinement of carriers within a QW preventing their non-radiative recombination. The negative slope in the EQE observed for the structures subjected to a GI is inherent to a decrease in the active volume of a QW. ${ }^{32}$ Both phenomena might be explained by the formation of islands through a partial selective etching of a QW in the $\mathrm{N}_{2}+\mathrm{H}_{2}$ atmosphere.

\subsubsection{TEM Investigations}

The aim of the TEM study was to analyze the effect of a GI on the morphology, thickness, strain and composition of the QWs presenting in the LED structures.

Figure 3 shows a bright-field (BF) CS (01̄10) images taken with $g=0002$ of the active region of the reference sample (LED-Ref) and the sample treated with a hydrogen (LED-H3). For the chosen imaging conditions, the layers with a different chemical composition exhibit a different contrast (the InGaN QWs appear in dark). The reference sample contains a QW in form of a 2D layer with planar morphology and homogeneous thickness (Fig. 3(a)). 
(a)

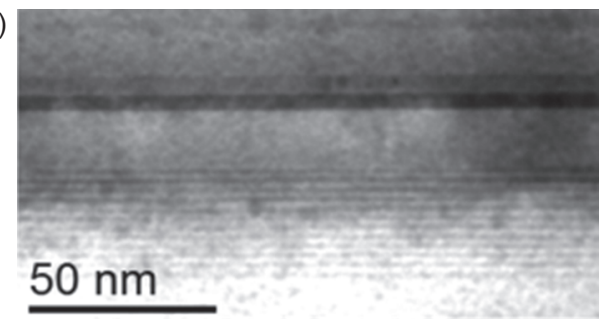

(b)

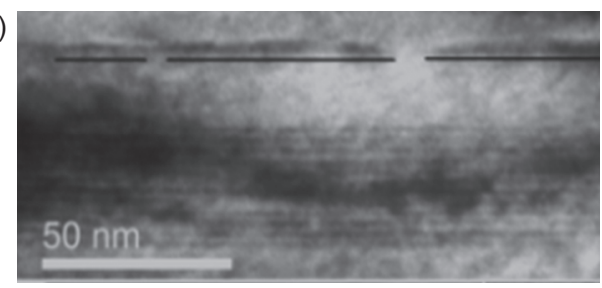

Fig. 3. Bright-field cross-sectional ( $0 \overline{1} \overline{1} 0)$ images taken with $g=0002$ of the LED structures grown without a GI ((a) LED-Ref) and with a GI in the $\mathrm{N}_{2}+\mathrm{H}_{2}$ atmosphere ((b) LED-H3).

We can see from Figure 3(b) that the QWs of the LED$\mathrm{H} 3$ sample form flat $3 \mathrm{D}$ islands rather than $2 \mathrm{D}$ layers. The islands have a lateral size varying from 15 to $60 \mathrm{~nm}$ and a height of $2.5 \pm 0.5 \mathrm{~nm}$. A conventional WBDF analysis (not shown) shows that no additional dislocations are present associated with the formation of islands in the active region of the LED-H3 sample.

A local thickness and composition of the InGaN QWs were measured using out-of-plane strain maps obtained by GPA of HRTEM images (Fig. 4). The HRTEM images were taken along the $(5 \overline{4} \overline{1} 0)$ zone axis giving the image of the (0002) planes only. The InGaN QWs appear in

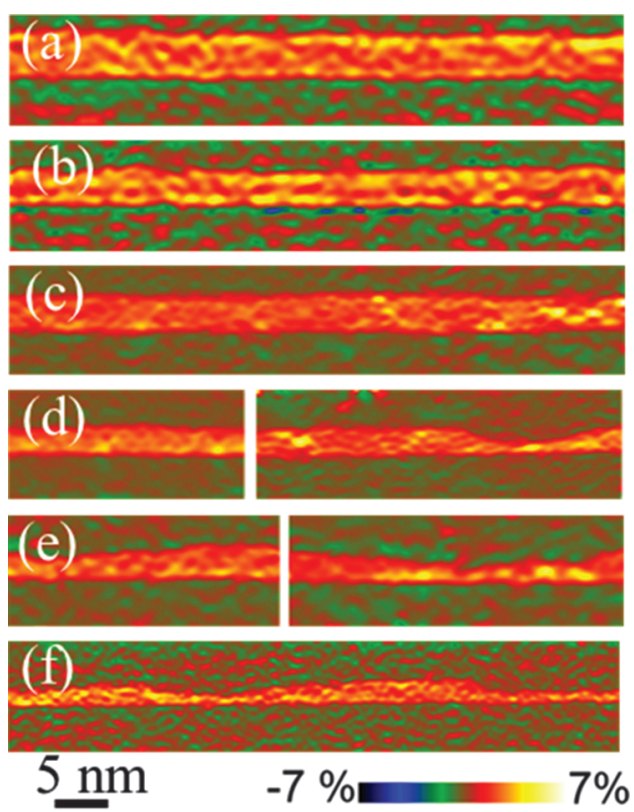

Fig. 4. GPA of the (5⿳亠丷厂甲10) HRTEM images: Maps of the out-of-plane strain in the QWs of the LED-ref (a), LED-H4 (b), LED-H1 (c), LEDH2 (d), LED-H3 (e), and LED-H6 (f) samples. red and yellow colour while the GaN matrix (taken as a reference) appears in green colour. A profile traced in the growth direction allows an accurate measurement of the layer thickness and the out-of-plane strain distribution within a QW. A chemical composition profile was calculated from Vegard's law and linear elasticity theory using the measured strain and corrected for a thin foil relaxation effect. The results for a QW thickness and composition are summarized in Table II.

The reference structure contains a $\mathrm{QW}$ in form of a $3.8 \pm 0.2 \mathrm{~nm}$-thick 2D layer (Fig. 4(a)) with indium composition of $18 \pm 1 \%$ (LED-Ref, Table II). The GI realized during $16 \mathrm{sec}$ in a $\mathrm{N}_{2}$ atmosphere or $3 \mathrm{sec}$ in a $\mathrm{N}_{2}+\mathrm{H}_{2}$ atmosphere under a $\mathrm{H}_{2}$ flow of $5.5 \mathrm{slm}$ has no impact on the QW morphology (Figs. 4(b), (c)) but results in the decrease in indium composition by $2 \%$ and in a $\mathrm{QW}$ thickness by several angstroms (LED-H4, LED-H1, Table II). An increase either in the GI time, or the hydrogen flow does not further affect the indium content but leads to the corrugation of a $2 \mathrm{D}$ layer surface characterized by the transformation of a flat QW surface into the wavy one (LED-H2, H3, and H6, Figs. 4(d)-(f)). In other words, a 2D layer is transforming into laterally connected islands. The effect is clearly dependent on a total GI impact, i.e. the longer the GI and the higher the $\mathrm{H}_{2}$ flow are, the stronger is the corrugation of the surface. The most pronounced corrugation is observed in the LED-H6 sample characterized by an evident decrease in the lateral size and the minimal thickness of islands (Fig. 4(f), Table II). As a consequence, the active volume of a $\mathrm{QW}$ decreases. A combination of the structural and electro-optical data indicates that the continuous transformation of a $2 \mathrm{D}$ layer into islands underlines the previously described optical and electro-optical properties of the QWs subjected to a GI in a $\mathrm{N}_{2}+\mathrm{H}_{2}$ atmosphere.

\section{CONCLUSIONS}

We have exploited a technological approach allowing a controlled modification of morphological, compositional and, hence, electro-optical properties of InGaN/GaN quantum wells. The method consists in the application of a GI in $\mathrm{N}_{2}$ or $\mathrm{N}_{2}-\mathrm{H}_{2}$ mixed atmospheres after the deposition of $\mathrm{In}_{0.18} \mathrm{Ga}_{0.82} \mathrm{~N}$ quantum well prior to its overgrowth by a GaN layer. The effect of a GI was studied using transmission electron microscopy, X-ray diffraction, photo- and electroluminescence techniques. We find a laterally inhomogeneous conversion of $\mathrm{InGaN}$ to $\mathrm{GaN}$ at the surface of a QW subjected to a GI. As a result, the initially flat surface of the QW becomes corrugated and the average QW thickness decreases. The effect can be controlled by a GI impact: the longer the GI and/or the higher the $\mathrm{H}_{2}$ flow, the stronger is the corrugation of the QW surface. At a sufficient $\mathrm{H}_{2}$ flow and/or GI time, a twodimensional InGaN layer transforms into laterally connected three-dimensional islands. Meanwhile, the average 
indium composition within a QW slightly decreases to $16 \%$ and is weakly affected by the GI impact. By tailoring the desired QW morphology and composition, the control over emission peak position is obtained within the blue spectral range from 450 to $490 \mathrm{~nm}$. The so-formed structures exhibit improved emission efficiency with respect to the reference structures containing $\operatorname{In}_{x} \mathrm{Ga}_{1-x} \mathrm{~N}$ QWs with $x \leq 18 \%$ overgrown immediately after their formation and emitting at the same wavelengths. The effect is related to a more effective localization of charge carriers within islands preventing their transport towards defect areas and, thus, their non-radiative recombination.

Acknowledgments: The research leading to these results has received funding from the European Union Seventh Framework Programme (FP7/2007-2013) under grant agreement No. 318388, from Ministry of Science and Education of Russia (agreement No. 02.G25.31.0014) and from RFBR.

\section{References and Notes}

1. S. Nakamura, S. J. Pearton, and G. Fasol, The Blue Laser Diode: The Complete Story, 2nd edn., Springer Verlag, Berlin (2000).

2. M. A. Moram, R. A. Oliver, M. J. Kappers, and C. J. Humphreys, Adv. Mater. 21, 3941 (2009).

3. T. Mukai, M. Yamada, and S. Nakamura, Jpn. J. Appl. Phys. 38, 3976 (1999).

4. J.-I. Hwang, R. Hashimoto, S. Saito, and S. Nunoue, Applied Physics Express 7, 071003 (2014).

5. M. Kumar, J. Park, Y. Lee, S. Chung, Ch. Hong, and E. Suh, Jpn. J. Appl. Phys. 47, 839 (2008).

6. Yu. Musikhin, D. Gerthsen, D.Bedarev, N. Bert, W. Lundin, A. Tsatsul'nikov, A. Sakharov, A. Usikov, Z. Alferov, I. Krestnikov, N. Ledentsov, A. Hoffmann, and D. Bimberg, Appl. Phys. Lett. 80, 2099 (2002).

7. H. Shim, R. Choi, S. Jeong, L. Vinh, C.-H. Hong, E.-K. Suh, H. Lee, Y.-W. Kim, and Y. Hwang, Appl. Phys. Lett. 81, 3552 (2002).

8. C. Soh, W. Liu, J. Teng, S. Chow, S. Ang, and S. Chua, Appl. Phys. Lett. 92, 261909 (2008)

9. Y. Sun, Y.-H. Choa, E.-K. Suh, H. Lee, R. Choi, and Y. Hahn, Appl. Phys. Lett. 84, 49 (2004).

10. Q. Wang, T. Wang, J. Bai, A. Cullis, P. Parbrook, and F. Ranalli, J. Appl. Phys. Lett. 103, 123522 (2008).

11. A. F. Tsatsulnikov, W. V. Lundin, E. E. Zavarin, A. E. Nikolaev, A. V. Sakharov, V. S. Sizov, S. O. Usov, Y. G. Musikhin, and D. Gerthsen, Semiconductors 45, 271 (2011).

12. A. F. Tsatsulnikov and W. V. Lundin, State-of-the-Art of Quantum Dot System Fabrications, edited by Dr. Ameenah Al-Ahmadi, InTech (2012), pp. 1-21. Available from: http://www.intechopen.com/books/ state-of-the-art-of-quantum-dot-system-fabrications/stimulated-formation -of-ingan-quantum-dots.
13. R. Oliver, G. Briggs, M. Kappers, C. Humphreys, S. Yasin, J. Rice, J. Smith, and R. Taylor, Appl. Phys. Lett. 83, 755 (2003).

14. S.-K. Choi, J.-M. Jang, S.-H. Yi, J.-A. Kim, and W.-G. Jung, Proceedings of SPIE 6479, 64791F (2007).

15. L. W. Ji, Y. K. Su, S. J. Chang, S. H. Liu, C. K. Wang, S. T. Tsai, T. H. Fang, L. W. Wu, and Q. K. Xue, Solid-State Electronics 47, 1753 (2003).

16. T. C. Wen, S.-C. Lee and W. I. Lee, Proceedings of SPIE 4278, 141 (2001).

17. X. H. Wu, C. R. Elsass, A. Abare, M. Mack, S. Keller, P. M. Petroff, S. P. DenBaars, J. S. Speck, and S. J. Rosner, Appl. Phys. Lett. 72, 692 (1998)

18. A. F. Tsatsul'nikov, E. E. Zavarin, N. V. Kryzhanovskaya, W. V. Lundin, A. V. Saharov, S. O. Usov, P. N. Brunkov, V. V. Goncharov, N. A. Cherkashin, and M. Hytch, Semiconductors 44, 1338 (2010).

19. K. Autor, (ed.), Fast MOVPE of III-nitride materials at superatmospheric pressure in horizontal flow reactor, Proceedings of 15th European Workshop on Metalorganic Vapour Phase Epitaxy (EWMOVPE XV), Aachen, Germany, June (2013).

20. W. V. Lundin, A. E. Nikolaev, M. Yagovkina, P. Brunkov, M. Rozhavskaya, B. Y. Ber, D. Y. Kazantsev, A. F. Tsatsulnikov, A. V. Lobanova, and R. A. Talalaev, J. Cryst. Growth 352, 209 (2012).

21. A. F. Tsatsulnikov, W. V. Lundin, A. V. Sakharov, E. E. Zavarin, S. O. Usov, A. E. Nikolaev, N. A. Cherkashin, B. Y. Ber, D. Y. Kazantsev, M. N. Mizerov, H. S. Park, M. Hytch, and F. Hue, Semiconductors 44, 93 (2010).

22. N. V. Kryzhanovskaya, W. V. Lundin, A. E. Nikolaev, A. F. Tsatsul'nikov, A. V. Sakharov, M. M. Pavlov, N. A. Cherkachin, M. J. Hÿtch, G. A. Valkovsky, M. A. Yagovkina, and S. O. Usov, Semiconductors 44, 828 (2010).

23. M. Hytch, E. Snoeck, and R. Kilaas, Ultramicroscopy 74, 131 (1998).

24. U. M. E. Christmas, A. D. Andreev, and D. A. Faux, J. Appl. Phys. 98, 073522 (2005).

25. W. V. Lundin, E. E. Zavarin, M. A. Sinitsyn, A. V. Sakharov, S. O. Usov, A. E. Nikolaev, D. V. Davydov, N. A. Cherkashin, and A. F. Tsatsulnikov, Semiconductors 44, 123 (2010).

26. Z. Gacevic, A. Das, J. Teubert, Y. Kotsar, P. K. Kandaswamy, T. Kehagias,T. Koukoula, P. Komninou, and E. Monroy, J. Appl. Phys. Lett. 109, 103501 (2011).

27. V. S. Sizov, A. F. Tsatsulnikov, A. V. Sakharov, W. V. Lundin, E. E. Zavarin, N. A. Cherkashin, M. J. Hytch, A. E. Nikolaev, A. M. Mintairov, Y. He, and J. L. Merz, Semiconductors 44, 924 (2010).

28. A. F. Tsatsulnikov, W. V. Lundin, A. V. Sakharov, E. E. Zavarin, S. O. Usov, A. E. Nikolaev, V. S. Sizov, A. L. Zakgeim, M. N. Mizerov, N. A. Cherkashin, and M. Hytch, Phys. Status Solidi C 9, 774 (2012).

29. T. Lu, Z. Ma, C. Du, Y. Fang, H. Wu, Y. Jiang, L. Wang, L. Dai, H. Jia, W. Liu, and H. Chen, Scientific Reports 4, 6131 (2014).

30. H. Wang, Z. Ji, S. Qu, G. Wang, Y. Jiang, B. Liu, X. Xu, and H. Mino, Opt. Express 20, 3932 (2012).

31. S. Saito, R. Hashimoto, J. Hwang, and S. Nunoue, Applied Phys. Express 6, 111004 (2013).

32. H. Li, P. Li, Junjie Kang, Z. Li, Y. Zhang, M. Liang, Z. Li, J. Li, X. Yi, and G. Wang, Applied Phys. Express 6, 092101 (2013). 